\title{
Determinants Choices of Drought Coping Strategies Among Boorana Pastoral Communities: The Case of Yabello Woreda, Oromiya Region, Southern Ethiopia
}

\author{
Gelgelo Wako Duba ${ }^{1,}$, , Solomon Tekalign², Tegegne Sishaw ${ }^{2}$ \\ ${ }^{1}$ College of Agriculture and Natural Resource Management, Gambella University, Gambella, Ethiopia \\ ${ }^{2}$ School of Geography and Environmental Studies, Haramaya University, Haramaya, Ethiopia
}

Email address:

galgewako61@gmail.com (G. W. Duba)

${ }^{*}$ Corresponding author

To cite this article:

Gelgelo Wako Duba, Solomon Tekalign, Tegegne Sishaw. Determinants Choices of Drought Coping Strategies Among Boorana Pastoral Communities: The Case of Yabello Woreda, Oromiya Region, Southern Ethiopia. American Journal of Life Sciences.

Vol. 9, No. 4, 2021, pp. 73-80. doi: 10.11648/j.ajls.20210904.13

Received: May 11, 2021; Accepted: July 22, 2021; Published: August 19, 2021

\begin{abstract}
Drought affects all pastoral and agro pastoral communities of the world, whose their livelihood is depend on rain water. It is one of the major constraints to sustainable livelihood of these communities in the arid and semi-arid areas. However, pastorals are using different coping strategies toward its impacts even though their choices are affected by different factors. The study was taken place in Yabello woredas of Boorana Zone, Southern Ethiopia to identify the major factors that affect choices of drought coping strategies by the pastoral and agro pastoral community. A survey was conducted among 288 sample pastoral and agro pastoral households in three kebeles of Yabello woredas area. The study was used mixed method, particularly the concurrent triangulation approach as research design. The study select sample kebeles and household from the districts by Multi stage sampling technique. Multinomial logit model was used to identify the factors which affect the pastoral drought coping strategies. Accordingly, Results from choice model employed indicate that gender, age, education level, market distance, credit, livestock size and income influence Pastorals and agro pastorals choices at $1 \%, 5 \%$ and $10 \%$ significance level. Moreover, the result revealed pastorals and agro pastorals whose livelihood depend on rainfall are significantly affected from impact of drought sensitivity with weakened coping strategies. To conclude, there is needed to improve the capability to cope with changing environmental conditions to offsets the negative impacts of droughts.
\end{abstract}

Keywords: Boorana Community, Coping Strategies, Drought, Logit Model, Yabello

\section{Introduction}

Drought is a slow-onset, creeping natural hazard that is a normal part of climate for virtually all regions of the world. Drought appears when rainfall in a region is less than statistical multi-year average for that region over an extended time period [25]. Drought, which originates from deficiency in precipitation over extended periods of time, affects approximately 60 percent of the world's population; hence it is one of the major constraints particularly in the arid and semi-arid lands [20].

Pastoralists over the years combated impacts of drought through different strategies. In the past, when land was vast and human population low; coupled with low frequency of drought, pastoral communities responded through mobility, temporary adoption of hunting and gathering [14]. Traditionally, the Boorana have been almost totally dependent for their livelihoods on the products of their cattle, using them as food or in trade for grain. In turn, the cattle depend on the stewardship of the Boorana people, as well as the regeneration of grazing lands through frequent and intense seasonal rains [1] However, the increase in drought impacts, more of these coping strategies have come to be no more help and survival needs, which results in deterioration and continued degradation of the environmental, diminish future adaptive capacity and livelihood options [26].

Today, in the face of land scarcity, exploding human populations and frequent occurrences of droughts, coping 
strategies are weakening and have been destroyed which has made Boorana pastoral community remain vulnerable to drought [1, 11, 32]. As households cope with changing climate and social structures, many of them are choosing to increase the diversity of their livelihood strategies to pastoral diversities and non-pastoral strategies [8]. However, poor infrastructural conditions hindered the access to education, water resources and market places [3]. [12] States conventional coping strategies are rapidly weakening to cope with the recent impacts of climatic threat including drought. The current study is aimed to identify the major factors which affect choices of coping strategies by pastorals community of Yabello woredas in southern Ethiopia.

\section{Materials and Methods}

\subsection{Description of the Study Area}

The study was conducted in Yabello woreda of Boorana zone in Oromia regional state. Yabello woreda is located between the $4^{\circ} 30^{\prime} 55.81^{\prime \prime}$ and $5^{\circ} 24^{\prime} 36.39^{\prime \prime} \mathrm{N}$ latitude and the $37^{\circ} 44^{\prime} 14.70^{\prime \prime}$ and $38^{\circ} 36^{\prime} 05.35^{\prime \prime}$ E longitude, at about 570 kilometers south of Addis Ababa (Figure 1). The total area of the woredas is about 31,4180 hectare $\mathrm{km}^{2}$ [30]. Altitudes range between 500 and 1500 meter above mean sea level. The major types of soil include chromic and orthic Luvisols, calcaric and eutric Fluvisols, and chromic, eutric and calcic Cambisols [6]. The study area comes under the influence of a bi-modal monsoon rainfall type, where $60 \%$ of the annual rainfall occurs during March to May (Ganna) and 40\% of it between September and October (Hagaya) [31]. The average annual temperature is about $24.5^{\circ} \mathrm{C}$. The corresponding amounts of maximum and minimum temperatures are $26.83^{\circ} \mathrm{C}$ and $20.4^{\circ} \mathrm{C}$ respectively [30].

The general vegetation-type is Acacia savanna, the major trees being A. drepanolobium on black cotton soil, and A. brevispica and A. horrida on the slopes. There are also patches of Balanites aegyptiaca, and several species of Commiphora and Terminalia at the lower altitudes. The higher parts of the hills were formerly covered with forest dominated by Juniperus procera and Olea europaea cuspidata. Endemic species of birds include Stresemann's bushcrow and white-tailed swallow found in the area [6].

Yabello Woreda has a total population of about 74,796. Of these 42,067 were males and the remaining 32,729 were females. The major inhabitants of the area constitute Oromo [30]. The major livelihood systems of the study areas depend on pure pastoralism $60 \%$ and $40 \%$ agro-pastoralism. The pastorals and agro pastorals in Boorana are presumably the owners of rich and respected cultural heritage and customary institutions, in which they are invoking for local governance, rules and regulations of social relationship and resource management. Nevertheless, the indigenous knowledge and customary institutions to manage the resource have been adversely challenged by different external political factors and natural phenomena like droughts [5].

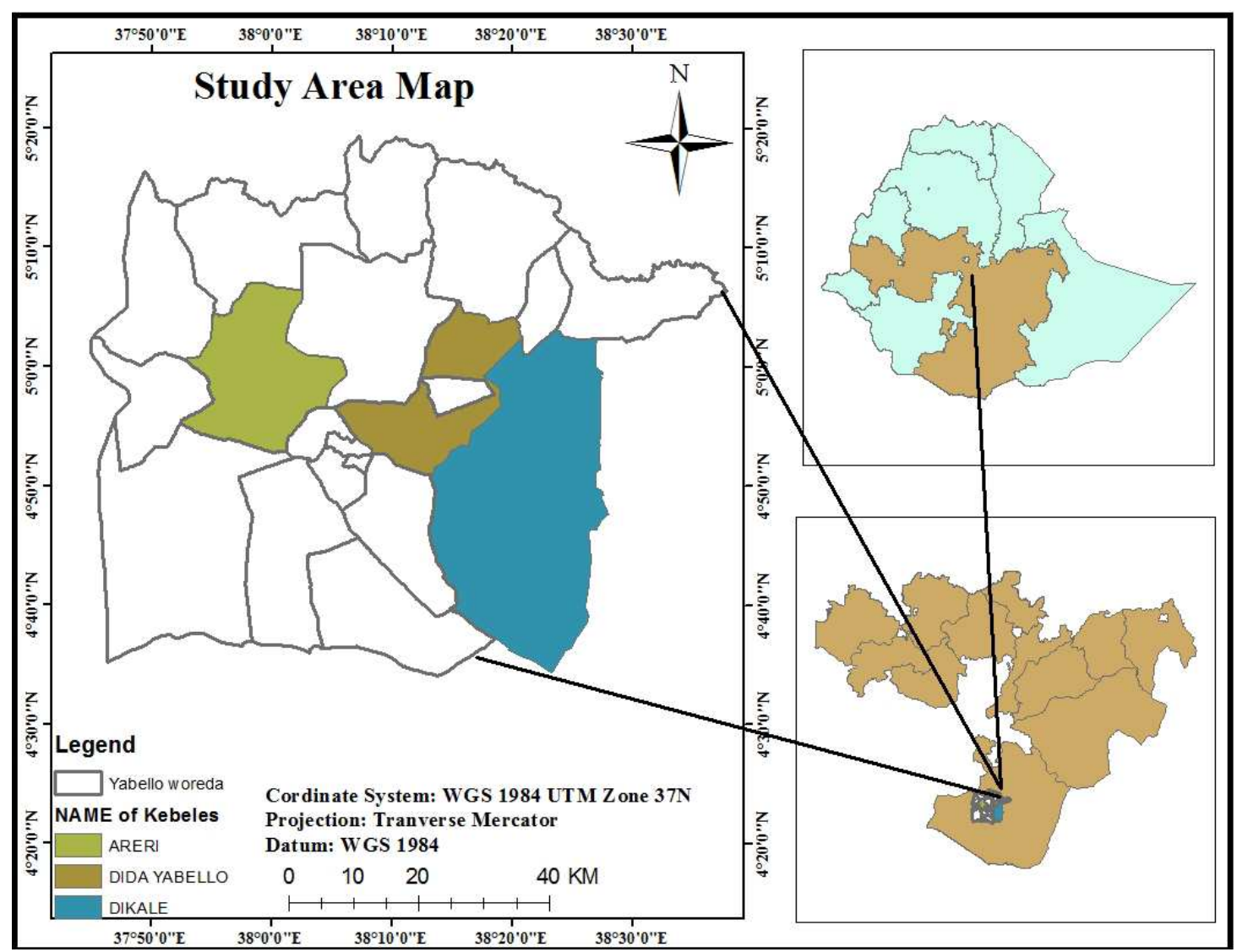

Figure 1. Location Map of the study area. 


\subsection{Research Design and Sampling}

The study was used mixed method, particularly the concurrent triangulation approach as research design. The purpose of mixed methods research is to build on the synergy and strength that exists between quantitative and qualitative research methods to understand a phenomenon more fully than is possible using either quantitative or qualitative methods alone [16]. Multi stage sampling technique was used to select sample kebeles and household from the district. The kebeles were stratified in two livelihood systems: Pastoralist dominated and agro pastoralist dominated kebeles. The sampling for the studies comprises all the one-thousand and eight hundred thirty five (1835) pastoralists and agro pastoralist in the three kebeles. From this, two hundred eighty eight (288) pastoralist and agro pastoralist were selected for the studies see (Table 1).

The sample populations from the three districts were taken using the following sample size formula developed by [23].

$$
s=X^{2} N P(1-P) \div d^{2}(N-1)+X^{2} P(1-P) .
$$

Where,

$\mathrm{s}=$ required sample size.

$\mathrm{X}^{2}=$ the table value of chi-square for 1 degree of freedom at 0.05 confidence level (3.841).

$\mathrm{N}=$ the population size.

$\mathrm{P}=$ the population proportion (assumed to be .50 since this would provide the maximum sample size).

$\mathrm{d}=$ the degree of accuracy expressed as a proportion (.05).

Table 1. Sample size of the Study Area.

\begin{tabular}{lll}
\hline District & Household heads & Sample size \\
\hline Dikale & 605 & 91 \\
Dida Yabello & 689 & 107 \\
Areri & 541 & 90 \\
Total & 1835 & 288 \\
\hline
\end{tabular}

\subsection{Data Analysis}

The multinomial logit (MNL) model is used to analyze the determinants of choice of coping strategies by the communities as used by $[24,19]$ to analyze the choices crop producers and [27] that of livestock herders to adapt to the negative impacts. The advantage of the MNL is that it permits the analysis of decisions across more than two categories, allowing the determination of choice probabilities for different categories $[29,9]$.

The household decision of whether or not to cope toward impact is considered under the general framework of utility or profit maximization. It is presumed that economic agents (like Pastoralists and agro-pastoralist) used coping options only when the perceived utility or net benefit from using a particular option is significantly greater than the benefit of the other strategy. In this circumstance, the utility of the economic agents is not observable, but the actions of the economic agents could be observed through the choices they made. Assuming that
$\mathrm{U}_{\mathrm{j}}$ and $\mathrm{U}_{\mathrm{k}}$ represent households' utility for two choices, $\beta j$ and $\beta k$, respectively, the linear random utility model could then be specified [17] as:

$$
\mathrm{U}_{\mathrm{j}}=\beta^{\prime} \mathrm{j} X \mathrm{i}+\varepsilon_{\mathrm{j}} \text { and } \mathrm{U}_{\mathrm{k}}=\beta_{\mathrm{k}}^{\prime} \mathrm{X}_{\mathrm{i}}+\varepsilon_{\mathrm{k}}
$$

where $U_{j}$ and $U_{k}$ are perceived utilities of coping options $j$ and $k$, respectively; $X_{\mathrm{i}}$ is the vector of explanatory variables which influence the perceived desirability of the option; $j$ and $k$ are the parameters to be estimated; and $\varepsilon j$ and $\varepsilon k$ are error terms assumed to be independently and identically distributed. For coping toward drought impact options, if a household prefers to use strategy $j$, then it follows that the perceived utility or benefit from strategy $j$ is greater than the utility from other options (say, $k$ ) depicted as:

$$
U_{i j}\left(\beta^{\prime} j X i+\varepsilon j\right)>U_{i k}\left(\beta^{\prime}{ }_{k} X_{i}+\varepsilon_{k}\right), j \neq k
$$

Based on the above relationship, it is possible to define the probability that a household will use option $j$ from among a set of coping strategy as follows:

$$
P\left(A_{i}=\frac{1}{X}\right)=P\left(U_{i j}>U_{i k / X}\right)
$$

To explain the MNL model, let $Y$ denote a random variable taking on the values $\{1,2, \ldots, \mathrm{J}\}$ for a positive integer $J$, and let $\mathrm{X}$ represent a set of conditioning variables. In this case, $\mathrm{Y}$ denotes options or categories of coping strategies, and $\mathrm{X}$ contains different households, institutional, and environmental attributes. The question is how, ceteris paribus, changes in the elements of $\mathrm{X}$ affect the response probabilities Prob $(A=j / x),, j=0,1, \ldots, J$. Because the probabilities must sum to unity, Prob $(A=\mathrm{j} / \mathrm{x}$,$) is determined$ once we know the probabilities:

$$
\text { For } \mathrm{j}=2 \ldots \mathrm{J} . \operatorname{Prob}(A i=j) \frac{e^{\beta k x i}}{\sum_{k=1}^{j} e^{\beta k x i}}, \mathrm{j}=0.2 \ldots . . \mathrm{j}, \beta \mathrm{o}=0
$$

Where $\beta_{\mathrm{j}}$ is a vector of coefficients of each of the independent variable $X_{i}, \beta_{k}$ is the vector of coefficient of the base alternative; $\mathrm{J}$ denotes the specific one of the $\mathrm{J}+1$ possible unordered choice and $6 \mathrm{j}$ is the indicator variable of choices.

Estimating equation (1) yields the $\mathrm{j}$ log-odds ratio is given by:

$$
\ln \left(\frac{\partial p_{i j}}{\partial p_{i k}}\right)=\mathrm{x}_{1}{ }_{1}\left(\beta_{\mathrm{j}}-\beta_{\mathrm{k}}\right)=\mathrm{x}_{\mathrm{i}} \beta_{\mathrm{j}}, \text { if } \mathrm{k}=0
$$

Note that the MNL coefficients are difficult to interpret and associating $\beta_{\mathrm{j}}$ with the $\mathrm{j}^{\text {th }}$ outcome is tempting and misleading. To interpret the effects of explanatory variable on probabilities marginal effects are derived [7]. The Marginal effects, or marginal probabilities, are functions of the probability itself. It measures the expected change in probability of a particular choice being made with respect to a unit change in an independent variable from the mean [17]. The marginal effect is derived as: 


$$
\delta_{\mathrm{j}}=\frac{\partial p_{j}}{\partial x_{i}}=\mathrm{p}_{\mathrm{j}}\left[\beta_{\mathrm{j}}-\sum_{K=O}^{J} \mathrm{P}_{\mathrm{k}} \beta_{\mathrm{k}}\right]=\mathrm{p}_{\mathrm{j}}\left(\beta_{\mathrm{j}}-\beta\right)
$$

The signs of the marginal effects and respective coefficients may be different, as the former depend on the sign and magnitude of all other coefficients. Therefore, every subsector of $\beta_{\mathrm{j}}$ enters every marginal effect both through probabilities and through weighted average that appear in $\delta_{j}$.

Multi-collinearity Diagnosis: As already discussed, MNL model was used to identify the determinants of the coping strategy in the study area. Prior to running the multinomial logit model, the hypothesized explanatory variables were checked for the existence of multi collinearity. Multi collinearity problem arises when at least one of the independent variables is perfect or is an exact linear relationship of the other independent variable [18]. The existence of multi collinearity might cause the estimated regression coefficients to have the wrong signs and smaller tratios that might lead to drawing the wrong conclusions. Therefore, it was important to check whether serious problems of multi collinearity existed among and between the potential continuous and discrete explanatory variables, of the model estimation.

Variance Inflation Factor (VIF) was employed to test the existence of multi-collinearity problem among explanatory variables. VIF shows how the variance of an estimator is inflated by the presence of Multi- Collinearity [18]. Each selected continuous explanatory variable $\left(\mathrm{X}_{\mathrm{i}}\right)$ is regressed on all the other continuous explanatory variables, the coefficients of determination $\left(\mathrm{R}^{2}\right)$ being constructed in each case. $\mathrm{R}^{2}$ is the adjusted square of the multiple correlation coefficients that result when the explanatory variable is regressed against all other. As a rule of Thumb, value of VIF greater than 10 is assumed often as a signal for the existence of multi-collinearity problem in the model [18]. VIF is computed as follow:

$$
\mathrm{VF}=\frac{1}{1-\mathrm{R}^{2}}
$$

Where VIF $=$ Variance Inflation Factor and $\mathrm{R}^{2}=$ the adjusted $\mathrm{R}$ square.

Likewise, contingency coefficients were computed to check the existence of multi-collinearity problem for discrete explanatory variables, which assumes a value between 0 and 1. There may be interaction between two qualitative variables, which can lead to the problem of high degree of association between two variables. The contingency coefficients are computed as follows:

$$
C=\sqrt{\frac{X^{2}}{N+X^{2}}}
$$

Where, $\mathrm{C}$ is Coefficient of contingency, $\mathrm{N}$ is total sample size and $\mathrm{X}^{2}$ is Chi-square random variable.

Dependent variable was identified by categorizing the sample households into livelihood strategy groups based on their choice of livelihood activities.

Independent Variables include age, gender, family size, level of education, landholding size, access to weather information, number of livestock holdings (TLU), income and access to such services as market, weather information, water and credit.

Table 2. Description of the independent variables.

\begin{tabular}{lll}
\hline Independent variables & Type of variables & Expected sign \\
\hline Age & Continuous & + \\
Credit & Dummy $(1=$ credit user, $0=$ otherwise $)$ \\
Education & Dummy $(1=$ can read \&write, $0=$ cannot $)$ \\
Family size & Continuous & + \\
Farm size & Continuous, (hectare $)$ & + \\
Income & Continuous (Birr $)$ & - \\
Info weather & Dummy $(1=$ have access, 0 otherwise $)$ \\
Livestock size & Continuous (TLU) \\
Market distance & Continuous, In number $(\mathrm{KM})$ \\
Sex & Dummy $(1$ if male, 0 otherwise $)$ \\
Water distance & Continuous, In number $(\mathrm{KM})$ \\
\hline
\end{tabular}

Detection of Multi-collinearity: The estimation of the multinomial logit model for this study was undertaken by normalizing one category, which is normally referred to as the reference category. In this analysis, the category (water and range land management strategy four) is the base category. The MNLM was run to see the determinants of different factors which influence the choices among the coping strategies. But the coefficients generated from MNLM direct only to the significant of the effect of the independent variables, so, the marginal effects from the MNL, which measure the expected change in probability of a particular choice being made with respect to a unit change in an independent variable, were reported and discussed.

Before running the model, it was useful to look into account the problem of multi collinearity among the independent variables. To this effect, all the eleven explanatory variables were checked for multi-collinearity. As indicated in (Table 3), VIF for all variables were less than 10 (1.05-2.94). Which indicate that multi-collineraity is not a serious problem in model estimation. Likewise, the results of the computation of contingency coefficients reveal that there was no serious problem of association among discrete variables (Table 4). Therefore, all the hypothesized explanatory variables were included in the model. Based on 
the VIF and contingency coefficients result, the data were found to have no serious problem of multi-collinearity and therefore the continuous and discrete explanatory variables were retained in the model.

Table 3. Variance inflation factor (VIF) for continuous explanatory variables.

\begin{tabular}{ll}
\hline \multirow{2}{*}{ Variables } & Collinarity statics \\
\cline { 2 - 2 } & Tolerance $\left(\mathbf{R}_{\mathbf{i}}^{\mathbf{2}}\right) \mathbf{V I F}$ \\
\hline Age & 0.5261 .902 \\
Family size & 0.5581 .793 \\
farm size & 0.2222 .385 \\
water distance & 0.3402 .941 \\
market distance & 0.5801 .725 \\
livestock size & 0.6521 .534 \\
Income & 0.9531 .050 \\
\hline
\end{tabular}

Source: Computed from the data of field survey, 2019.

Table 4. Contingency coefficients for discrete explanatory variables.

\begin{tabular}{l}
\hline Variables COP SEX LEVELD CRED WETINF \\
\hline COP 1.000 \\
SEX 0.0151 .000 \\
LEVED $-0.080-0.0761 .000$ \\
CRED $-0.183-0.015-0.0581 .000$ \\
WETINF $0.230 .008-0.0080 .5501 .000$ \\
\hline
\end{tabular}

Source: Computed from the data of field survey, 2019.

\section{Result and Discussion}

\subsection{Determinants Choices of Drought Coping Strategies}

The result indicates gender has significant and positive effects of choosing coping strategy for drought impact. Maleheaded households cope more readily to the impact, 70\% more likely chooses livestock diversification and $9 \%$ more likely engage in Agro pastoral livelihood diversification pausing the value of other variables persistent. This means that the probability of male head household choosing the coping strategy (livestock diversification and integrated agro pastoral livelihood diversification) are increases by 0.7 and 0.9 respectively, which is relative to strategy two than female household heads for coping toward drought impact see Table 5. Households headed by female have more responsibilities in activities undertaken with in the family. As far as those low return activities are undertaken around the homes which have ties with women responsibilities, female household heads have more tendency of engaging in home activities than their male counterpart. Another possible reason is that female's difference in natural and physical capabilities, the male households can choose the livestock diversification strategy and agro pastoral livelihood diversification respectively. This finding corroborate with other finding $[8,11,13]$.

\subsection{Age of Household Heads}

Age of the household head, represents experience, affected coping to the drought impact. For instance, a unit increases in age of the household head results in a $1.1 \%$ increase in the probability of choosing NFNP practices and $1.7 \%$ increase in crop livestock livelihood diversification. The increment age of household by one year, decreases the probability of involving in Livestock diversification by $0.2 \%$ Table 5 . Because, the increase in the age of the household head, increases the likelihood of the household, to manage both crop and livestock at the same time with life experiencing and also livelihood diversification which may participate in activities of NFNP practices. This study support with other findings [22] that stated age of the household head gets older, the burden on availability of labour force would increase and the household may have to carry out livestock production and other income generating activities.

Table 5. Determinants of Pastoral Coping Strategies for Drought Impacts.

\begin{tabular}{llll}
\hline Variables & $\begin{array}{l}\text { Livestock diversification } \\
\text { ME Coefficient (SE) P-value }\end{array}$ & $\begin{array}{l}\text { Nonfarm, non-pastoral practices } \\
\text { ME Coefficient (SE) P-value }\end{array}$ & $\begin{array}{l}\text { Agro pastoral livelihood diversification } \\
\text { ME Coefficient (SE) P-value }\end{array}$ \\
\hline Sex & $0.7081 .407 * * * 0.00$ & -0.4106 .630 .97 & $0.0991 .022 * 0.07$ \\
Age & -0.0020 .4370 .26 & $0.0110 .023 * 0.02$ & $0.0170 .019 * * * 0.00$ \\
Education & 0.03756 .8400 .98 & $0.4730 .547 * * 0.00$ & 0.14243 .1950 .97 \\
Family size & 0.0250 .8620 .26 & 0.0140 .3870 .38 & $0.2050 .515 * * * 0.00$ \\
Weather inf & 0.0420 .6220 .98 & 0.3423 .0440 .25 & 0.0320 .6140 .99 \\
Credit & $0.1171 .036 * 0.02$ & $0.4020 .550 * * 0.00$ & -0.16662 .7610 .96 \\
Farm size & 0.0040 .2510 .39 & 0.0470 .1410 .28 & -0.02330 .1740 .45 \\
Water distance & 0.0040 .1360 .21 & 0.0120 .0750 .31 & 0.0080 .0740 .65 \\
Market distance & 0.0010 .0410 .29 & $0.0040 .025 * * 0.00$ & $0.0070 .024 * 0.06$ \\
Livestock size & $0.0010 .005 * 0.03$ & -0.0010 .0120 .16 & $0.0020 .012 * * 0.04$ \\
Income & $0.0000 .002 * * 0.05$ & -0.0000 .0000 .23 & $0.0020 .001 * * 0.04$ \\
\hline
\end{tabular}

Notes: ME: Marginal effect; SE coefficient of standard error in parentheses; ${ }^{*} \mathrm{P}<0.1 * * \mathrm{p}<0.05 * * * \mathrm{p}<0.01 \mathrm{LR}^{\mathrm{c}} \mathrm{chi}^{2}(30)=294.10$

Number of observation $=288$ Pseudo R2 $=0.3785$

Log likelihood $=-241.4235$ Prob $>$ chi2 $=0.0001$. Gender of house hold heads.

\subsection{Education}

Education of the head of household increases the probability of coping towards the impact of drought. An increase the education of the household head by one unit increases the probability of choosing nonfarm non pastoral practices as a coping strategy by $4.7 \%$ percent. Moreover, almost all of the marginal values of education are positive across all coping options indicating the positive relationship between educations and Coping strategy toward drought impacts. This result agrees with [9] finding states that 
education has positive relation with coping strategy.

\subsection{Family Size}

As an increase in number of family size, increases the probability of choosing agro pastoral livelihood diversification by $20.5 \%$ percent. The higher number of family size enables the households, managing both crops and livestock's, through the labour in the family. As the large size of households, there is better chance of coping toward drought impact. This result agrees with studies of $[15,13]$. Even though the remaining strategy has positive sign, the household size doesn't significantly enhance the chance of selecting those strategies, towards drought impact.

\subsection{Access to Credit}

The result indicates that Access to credit has a positive and significant impact on pastoral coping strategy. As the access of the credit is available, the probability of pastoral to use livestock diversification and nonfarm non pastoral practices increases by $11.7 \%$ and $40.2 \%$ respectively. This may be due to fact that still some pastoralists do not want to sell livestock for investment in non-pastoral sector because of the social prestige associated by owning large number of livestock. The utilization of credit may help them to invest in high return NPNF activities because credit service providers give them technical know, how in investing that money into productive activities but not only money. Credit delivers different prospects to engage in various coping strategies including livestock herd splitting and exchange, herd diversification based coping strategies, petty trade and also other Generally, it provides opportunities to employ all possible coping strategies to overcome the devastating risk of drought impact. In line with this study [2, 28] states access to credit is an important determinant for enhancing the adoption of various strategies to coping.

\subsection{Livestock Size}

The result shows the use of livestock diversification and crop-livestock livelihood diversification has positive and significant effects on Livestock size. As the livestock size increase by one TLU the probability of choosing livestock diversification and crop-livestock livelihood diversification increases by $0.1 \%$ and $0.2 \%$ respectively holding the value of other variables constant. The positive relationship is explained by the fact that livestock size being a proxy for the pastoralists resource endowment, those sample respondents with large livestock size have better chance to earn more income. This study is in line with the reality in Boorana pastoralist where the strategies of herd splitting, changing species composition, destocking, livestock migration and herd splitting is higher for the household with larger livestock holding. For example see [31, 11].

\subsection{Market Distance}

The result from this study indicated that as market distance increase by one kilometer the probability of choosing nonfarm non pastoral practices and crop livestock livelihood diversification increases by $0.4 \%$ and $0.7 \%$ holding the value of other variables constant. The possible justification could be that the households who are closer to the market centers incur fewer costs to access market incentive for nonfarm non pastoral practices and integrated livelihood diversification. Therefore, a long distance to the nearest market reduces the probability of participating like destocking, especially during drought time. This study is in line with $[10,13]$.

\subsection{Income}

Income is positively affects the probability to choose livestock diversification and the probability of choosing nonfarm non pastoral practices. A unit increase an income increases the probability livestock diversification and integrated crop livestock livelihood diversification by $0.2 \%$ and $0.1 \%$ respectively Table 4 . The income shows positive relationship with strategies of the nonfarm non pastoral practices. This indicate that when pastoralists have options pastoral/ non pastoral income, can afford to diversify the herds, and exchanges and increase the capacity of pastoral to use integrated crop and livestock farming and can use less of nonfarm non pastoral practices like petty trading, selling of charcoal and town migration for town labor.

\section{Conclusion}

Pastoralist in the Boorana lowlands Ethiopia employs several coping strategies toward the impacts of recurrent drought. These strategies are household and site specific due to variations in household characteristics and site condition. This study identified several factors that affect pastoralist' choices of certain strategies, which can be grouped in three major factors: livestock diversification, Non-farm non pastoralist's practices and Agro pastoral livelihood strategies. Even though the pastoralists are using different coping mechanism the strategies desired by the households are not without constraints and influence by different factors positively and negatively influencing the coping strategies of the pastoralists and agro pastoralists. As pastorals level of education is increasing the chances he got to use different coping. Indeed using agro pastoral practices together result from ones knowledge skills which Educating pastorals will enhance the knowledge to use different coping strategies and change with changing environments. Markets distances always affect pastorals livelihoods. During drought time the far market distances the harder livestock's rich the market. This is due to livestock's can't go far distances during severe drought episode. So to strength pastorals coping strategies market near their kebeles is essential. Water distances are another important factor which influences the coping strategies of pastorals. The source of water is rainfall for all kebeles. As drought induced its impacts all water storage became empty and made livestock go to long distances, so other sources of water is important near the villages of pastorals to overcome the influence from their coping strategies.

Generally level of education, Family size, market distance 
and credit positively affect all the strategies whereas Sex, Age, Weather information, Credit and livestock size negatively influence on some of the coping strategies choices of the pastoralists. Significance of the variables are exists on sex, age, family size, credit, market distance and income whereas the left weather information, water distance and farm size didn't show any significance on coping strategies. So, as the severity of drought impacts is increasing the capacity of the pastoralists and agro pastoralists to cope toward the impact is becoming weakened and being influenced by different factors.

\section{References}

[1] Angasse, A. and Oba, G. (2007). Herder perceptions on impacts of range enclosure, crop farming, fire ban and bush encrochement on the rangelands of Borana, South western Ethiopia. Human Ecology 36, 201-215.

[2] Asnake, W. (2010). Participation into Off-Farm Activities in Rural Ethiopia: Who Earns More? Masters of Arts in Development Studies; International Institute of Social Studies.

[3] Beddada K, Eshetu Z, Assefa E, Gugsa E. (2015). Community Based Resilience Analysis Assessment Report Yabello District, Oromia Regional State, Ethiopia. African Centre for Disaster Risk Management (ACDRM). 2015.

[4] Berhanu, W., Colman D. and Fikadu, B. (2008). Diversification and Livelihood Sustainability in a Semi-arid Environment: A Case Study from Southern Ethiopia. Journal of Development Studies 43 (5): 871-889.

[5] BoZA (Borana Zone Administration). 2013. Annual report of 2012-2013. Yabello, Ethiopia.

[6] Borana Zone pastoral development office Report.

[7] C. Funk., G. Senay., A. Asfaw., J. Verdin., J. Rowland., J. Michaelson., G. Eilerts., D. and Korecha. Choulart (2005). on. Recent drought tendencies in Ethiopia and equatorial subtropical eastern Africa. FEWS-NET, Washington DC 2005.

[8] D, Skinner. (2010). Rangeland management for improved pastoralist livelihoods the Borana of southern Ethiopia. MA thesis. Oxford Brookes University.

[9] Deressa Temesgen T., R. M. Hassan, C., Ringler, Tekie. and Alemu, M. Yusuf. (2009) Determinants of farmers' choice of adaptation methods to climate change in the Nile BasinofEthiopia. GlobalEnvironmentalChange doi: 10.1016/j.gloenvcha.2009.01.002.6.

[10] Dilruba, K. Roy. BC. (2012). Rural Livelihood Diversification in West Bengal: Determinants and Constraints for Upward Mobility? Evidence from a Panel Data Study in Ethiopia. World Development 40 (8): 1634-1646.

[11] Dirriba Mengistu and Jema Haji. (2015). Factors Affecting the Choices of Coping Strategies for Climate Extremes: The Case of Yabello District, Borana Zone, Oromia National Regional State, Ethiopia. International Journal of Engineering Innovation \& Research 3 (4), 129-136. DOI: 10.11648/j.sr.20150304.11.

[12] Dirriba Mengistu. (2016). Impacts of Drought and Conventional Coping Strategies of Borana Community,
Southern Ethiopia, Research on Humanities and Social Sciences ISSN (Paper) 2224-5766 Vol. 6, No. 23, 2016.

[13] Doyo Kena., Eric, N. and Tesfaye Lemma. (2018). Livelihood diversification strategies among the Borana pastoral households of Yabello District, Oromia Region, Ethiopia. Journal of Agricultural Extension and Rural Development Vol. 10 (10), pp. 211-221, October 2018.

[14] Fratkin, E. (2001). East African pastoralism in transition: Maasai, Boran and RendilleCases. African Studies Review, 44 (3) $1-25$

[15] Fufa, M. (2015). Factors Responsible for Income Diversification among Rural Farm Households in Agarfa District, Bale Zone, Oromia National Regional State, Ethiopia. Master's Thesis, Haramaya University, Ethiopia.

[16] Gay, mills and Airsian (2009) Educational research; competences for analysis and application $9^{\text {th }}$ edition.

[17] Greene, W. H. (2000). Econometric Analysis. Fourth Edition. Pretice Hall International, Inc. New York.

[18] Gujarati, D. (2003). Essentials of Econometrics, second edition, Mc Graw Hill, pp. 449-454. New York.

[19] Hassan, R., and Nhemachena, C., (2008). Determinants of African farmers' strategies for adapting to climate change: multinomial choice analysis. African Journal of Agricultural and Resource Economics 2 (1), 83-104.

[20] Huho, JM., and Mugalavai EM (2010). The Effects of Droughts on FoodSecurity in Kenya. The International Journal of Climate Change: Impacts Resp. 2 (2): 61-72.

[21] Hurst, M., N. Jensen., S. Pedersen., A, Sharma. and J. Zambriski, (2012). Changing climate adaptation strategies of Borana pastoralists in southern Ethiopia. CGIAR Research Program on Climate Change, Agriculture and Food Security CCAFS. Working paper No. 15 Cali, Colombia.

[22] Indris Siraje and Adam Bekele. (2013). Assessment of Food Insecurity and Coping Mechanisms among Pastoral Households of Afar National Regional State: The Case of Chifra District, Ethiopia.

[23] Krejcie and morgan, D. W. (1970). Determining sample size for research activities. Journal of educational and psychological measurement, 30 (10) 607-610.

[24] Kurukulasuriya, Mendelsohn. (2008). A Ricardian analysis of the impact of climate change on African cropland. African Journal of Agricultural and Resource Economics 2 (1), 1- 23.

[25] Mala, S., Mahesh, K. J. and Parul, P. (2014). An Approach to analyze Droughtoccurrences using Geospatial Techniques, $15^{\text {th }}$ ed Esri India User Conference 2014.

[26] Riche, B., Hachilek, E. and Cynthia, B. A. (2009). Climaterelated vulnerability and adaptive capacity in Ethiopia's Borana and Somali communities, International Institute for Sustainable Development Final assessment report, Commissioned by SAVE the Children UK and CARE Ethiopia, Unpublished.

[27] Seo, N. and R. Mendelssohn. (2008). Animal husbandry in Africa: Climate change impacts and adaptations. African Journal of Agricultural and Resource Economics 2 (1): 6582. Series 11. Chatham, UK: Natural Resources Institute. 
[28] Temesgen, A. (2010). Climate change to conflict. Lessons from southern Ethiopia and northern Kenya. Fafo Report 2010:09.

[29] Wooldridge, J. M. (2002). Econometric analysis of cross section and panel data. Cambridge, Mass.: MIT Press.

[30] YWAO (Yabello woredas Administration Office), (2018) Annual report 2017/2018. Yabello, Ethiopia.
[31] Zemenu mintesinot 2009 bush encroachment mapping using supervised classification and spectral mixture analysis in Borana Range lands; case study in Yabello woredas. $\mathrm{PhD}$ Thesis, Adis Abeba University.

[32] YWDRMO (Yabello woredas Disaster risk management Office) Annual report on 2017/18 droughts Yabello, Ethiopia. 